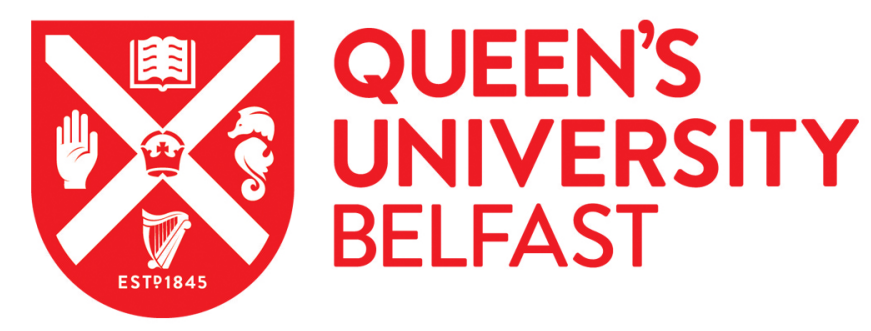

\title{
A comparative study of hole making performance by coated and uncoated WC/Co cutters in helical milling of Ti/CFRP stacks
}

Li, S., Qin, X., Jin, Y., Sun, D., \& Li, Y. (2018). A comparative study of hole making performance by coated and uncoated WC/Co cutters in helical milling of Ti/CFRP stacks. International Journal of Advanced Manufacturing Technology, 94(5-8), 2645-2658. https://doi.org/10.1007/s00170-017-0842-8

Published in:

International Journal of Advanced Manufacturing Technology

Document Version:

Peer reviewed version

Queen's University Belfast - Research Portal:

Link to publication record in Queen's University Belfast Research Portal

Publisher rights

Copyright Springer Verlag 2017. This work is made available online in accordance with the publisher's policies. Please refer to any applicable terms of use of the publisher.

\section{General rights}

Copyright for the publications made accessible via the Queen's University Belfast Research Portal is retained by the author(s) and / or other copyright owners and it is a condition of accessing these publications that users recognise and abide by the legal requirements associated with these rights.

Take down policy

The Research Portal is Queen's institutional repository that provides access to Queen's research output. Every effort has been made to ensure that content in the Research Portal does not infringe any person's rights, or applicable UK laws. If you discover content in the Research Portal that you believe breaches copyright or violates any law, please contact openaccess@qub.ac.uk. 


\title{
A comparative study of hole making performance by coated and uncoated $\mathrm{WC} / \mathrm{Co}$ cutters in helical milling of Ti/CFRP stacks
}

\author{
Shipeng $\mathrm{Li}^{\mathrm{a}}$, Xuda Qin*a ${ }^{\mathrm{a}}$, Yan Jin ${ }^{\mathrm{b}}$, Dan Sun ${ }^{\mathrm{b}}$, Yonghang $\mathrm{Li}^{\mathrm{c}}$
}

${ }^{a}$ Key Laboratory of Mechanism Theory and Equipment Design of Ministry of Education, Tianjin University,

Tianjin 300350, PR China.

${ }^{\mathrm{b}}$ School of Mechanical and Aerospace Engineering, Queen's University Belfast, Belfast BT9 5AH, UK.

${ }^{\mathrm{c}}$ Beijing Aeronautical Science and Technology Research Institute, Commercial Aircraft Corporation of China Limited, Beijing 102211, PR China.

*Corresponding author.

School of Mechanical Engineering, Tianjin University, Yaguan Road 135, Jinnan, Tianjin 300350, PR China.

E-mail address: qxd@tju.edu.cn. 


\section{Abstract}

Carbon fiber reinforced plastic (CFRP) and titanium alloy stacks are typical difficult-to-machine materials and often results in rapid tool wear, leading to a low drilling efficiency in aircraft assembling. Helical milling process has demonstrated its superior performance in making holes in these materials, but selecting a proper cutting tool is still a great challenge and little research has been carried out to investigate the effect of different coatings on tools performance. Therefore, in this paper, milling tools with and without coatings (diamond coating, TiAlN $+\mathrm{AlCrN}$ multilayer coating and TiAlN coating) were employed in helical milling of Ti/CFRP stacks. The cutting performance and the degradation mechanisms of these milling tools were investigated in details. It is found that, uncoated tools demonstrate the best cutting performance with lowest cutting force, highest hole quality and slightest tool wear. Degradation of nitride coated tools is due to the combined effects of increased roundness of cutting edge and the strong dependence of cutting performance on the tool sharpness. Diamond coated tools showed the greatest degradation, which has been attributed to the low materials ductility at tool cutting edge, weak adhesive strength between the coating and substrate, and the poor thermal resistance of the diamond coating.

Keywords: Helical milling; Ti/CFRP stack; Hard coatings; Tool wear; WC/Co tool. 


\section{Introduction}

Due to the high strength-to-weight ratio, carbon fiber reinforced plastic/Ti alloy (Ti/CFRP) stacks are extensively used in the aircraft industry [1-3]. Hole-making process accounts for $40-60 \%$ of material removal in aircraft assembly [4] and such operation not only determines the total machining time but also strongly affects the reliability of the aircraft [5].

Conventional drilling is by far the most common hole-making process for Ti/CFRP stacks. However, the hole quality produced through drilling is far from ideal due to the large cutting force and high cutting temperature. As a result, additional post-drilling processes (such as trimming edges, clean-up, disassembly/reassembly, etc.) are often required [6,7], which subsequently increase the total processing time. Helical milling (also known as orbital drilling) is an emerging hole-making technology, by which the hole is milled with a small contact area. As much lower force and temperature are generated during this process, better hole quality can be achieved without deploying redundant post processing, hence hole-making efficiency can be greatly improved [8-12].

In hole making processes for Ti/CFRP stacks, the low thermal conductivity, low deformation coefficient and high chemical reactivity of titanium alloys often result in severe tool wear $[13,14]$, while the high hardness of carbon fibers in CFRP also poses a great challenge to the tool durability [15-18]. In spite of numerous advantages of the helical milling process, rapid tool wear still occurs in milling of Ti/CFRP stacks [19], leading to reduced processing quality. 
Wear resistant coatings have been applied widely in machining aircraft materials to enhance the tool durability. Pecat et al. [20] showed that AlCrN coating and hard carbon coating can reduce tool flank wear significantly in low frequency vibration assisted drilling of CFRP/Ti6Al4V. Zitoune et al. [21] found that nc-CrAlN/a-Si3 $\mathrm{N}_{4}$ coated tool could decrease the cutting force and improve the finishing surface roughness in drilling of CFRP/Al stacks. Park et al. [22] verified the advantages of boron-aluminum-magnesium (BAM) coating in drilling of CFRP/Ti stack at high cutting speed, such as less Ti adhesion and lower tool wear. On the other hand, some research showed that coated tools may not always produce promising results. According to the investigation of Mruphy et al. [23], TiN coated and DLC coated tools produced higher thrust forces and lower diameter accuracy compared with uncoated tool in machining of carbon-epoxy composites. Wang et al. [24] found that in drilling of CFRP, AlTiN coating offered no benefit but a high thrust force and a large wear volume. Shyha et al. [25] claimed that TiN coated drill bits have shorter tool life than uncoated drill. Qin et al. [14] found diamond coated tool produced serious coating flaking in helical milling of $\mathrm{Ti}$ alloys and therefore it is not recommended for the hole making process of $\mathrm{Ti}$ alloys.

To date, literature concerning tool coating performance in machining of stack material has been mainly focused on the drilling process. Although a few studies have deployed coated tools in helical milling of alloy or composites [12,26,27], the role of different coatings in helical milling of Ti/CFRP stack is still lacking. Since helical milling is increasingly used in aircraft assembling, it is necessary to systematically 
evaluate the coated tool performance and understand their degradation mechanisms in helical milling of Ti/CFRP stacks.

In this paper, coated (diamond, TiAlN $+\mathrm{AlCrN}$ and TiAlN) and uncoated tools were used for helical milling of Ti/CFRP stacks. The associated cutting forces, hole qualities and tool wear are investigated systematically and the detailed tool degradation mechanisms are discussed.

\section{Experimental details}

$5 \mathrm{~mm}$ thick titanium alloy (Ti6Al4V) plate was placed on top of $5 \mathrm{~mm}$ multidirectional CFRP (consisting of T800 carbon fiber and epoxy matrix) to form a typical Ti/CFRP stack structure, which was bolted to a dynamometer. The plate size is $120 \mathrm{~mm} * 250 \mathrm{~mm}$. The milling tools were prepared from WC-12\%Co cemented carbides with ultrafine grains with or without coatings. The morphology of uncoated (UC), diamond coated (DC), TiAlN+AlCrN multilayer-coated (TAC) and TiAlN (TC) coated end mills were investigated using a scanning electron microscope (SEM, FEI Quanta 250FEG) and a VHX-5000 3D optical microscope. Figure 1 shows the optical images of a typical uncoated helical milling tool. There was no edge preparation before coating deposition for these coated tools. Figure 2 shows the cross-sectional images of coated tools. Further specifications and geometries of the milling tools are listed in Table 1 and Table 2, respectively. The geometries of all tools are the same. 

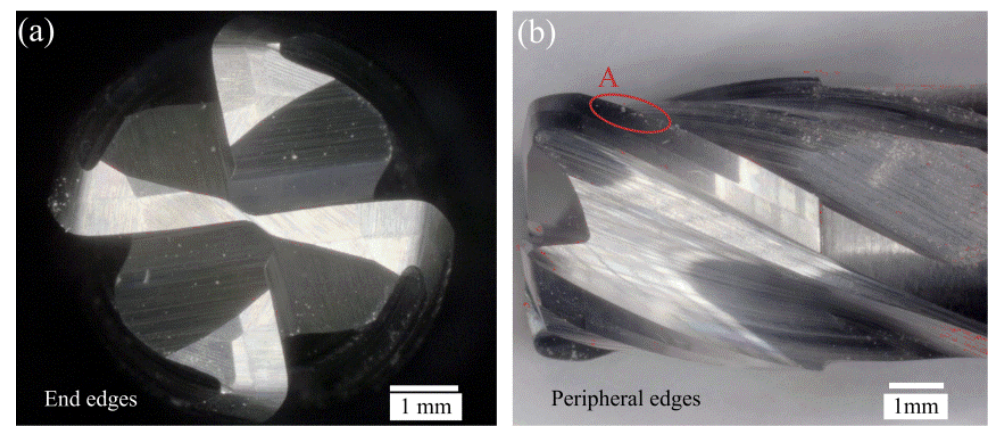

Fig. 1 Optical images of helical milling tool without coating
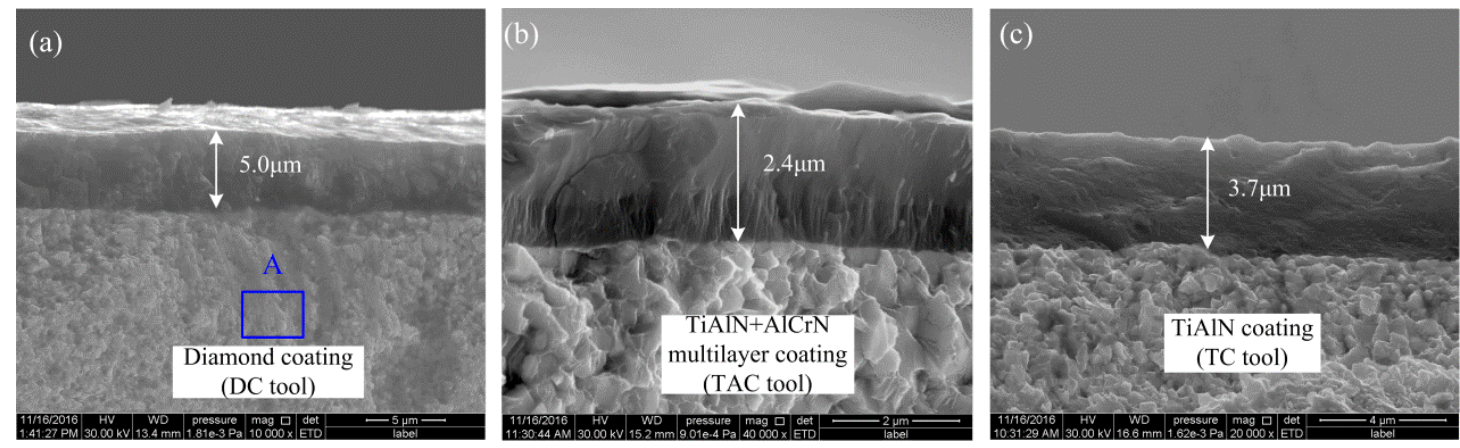

Fig. 2 Cross-sectional SEM images of a diamond coating, b TiAlN + AlCrN multilayer coating and c TiAlN coating

Table 1 Specifications of tool coatings

\begin{tabular}{cccc}
\hline & Diamond coating & $\begin{array}{c}\text { TiAlN }+ \text { AlCrN } \\
\text { multilayer coating }\end{array}$ & TiAlN coating \\
\hline Hardness & $>5000 \mathrm{Hv}$ & $\sim 3300 \mathrm{Hv}$ & $\sim 3200 \mathrm{Hv}$ \\
Thickness & $5 \sim 7 \mu \mathrm{m}$ & $2 \sim 4 \mu \mathrm{m}$ & $3 \sim 5 \mu \mathrm{m}$ \\
\hline
\end{tabular}

Table 2 Milling tool geometries

\begin{tabular}{lllllll}
\hline $\begin{array}{l}\text { Tool } \\
\text { diameter }\end{array}$ & $\begin{array}{l}\text { Number } \\
\text { of flutes }\end{array}$ & $\begin{array}{l}\text { Rake } \\
\text { angle }\end{array}$ & $\begin{array}{l}\text { Clearance } \\
\text { angle }\end{array}$ & $\begin{array}{l}\text { Helix } \\
\text { angle }\end{array}$ & $\begin{array}{l}\text { Length of } \\
\text { cut }\end{array}$ & $\begin{array}{l}\text { Length } \\
\text { overall }\end{array}$ \\
\hline $6 \mathrm{~mm}$ & 4 & $5^{\circ}$ & $15^{\circ}$ & $35^{\circ}$ & $6 \mathrm{~mm}$ & $55 \mathrm{~mm}$ \\
\hline
\end{tabular}


Helical milling was carried out on a DMC75V linear five-axis machining center. Cutting chips were removed using an industrial vacuum cleaner. Cutting forces were measured by a Kistler 9257A dynamometer and a supporting Kistler5070 charge amplifier, as shown in Fig. 3. The diameter of machined holes was $10 \mathrm{~mm}$. Due to the different properties, the optimum machining parameters for Ti alloys and CFRP vary widely. To give a comprehensive consideration to both materials, the varying machining strategy was employed in the experiment. When the axial feed reached $5.2 \mathrm{~mm}$ (a little thicker than $\mathrm{Ti}$ plate), cutting condition of $\mathrm{Ti}$ alloys switched into cutting condition of CFRP, as shown in Fig. 3b. At this time, CFRP was actually machined a little $(0.2 \mathrm{~mm})$, which is to avoid using high spindle speed before Ti plate was milling through. The varying machining strategy is proved to be beneficial to prolong tool life and improve hole quality. The cutting conditions have been listed in Table 3. There was not any coolant during the tests.
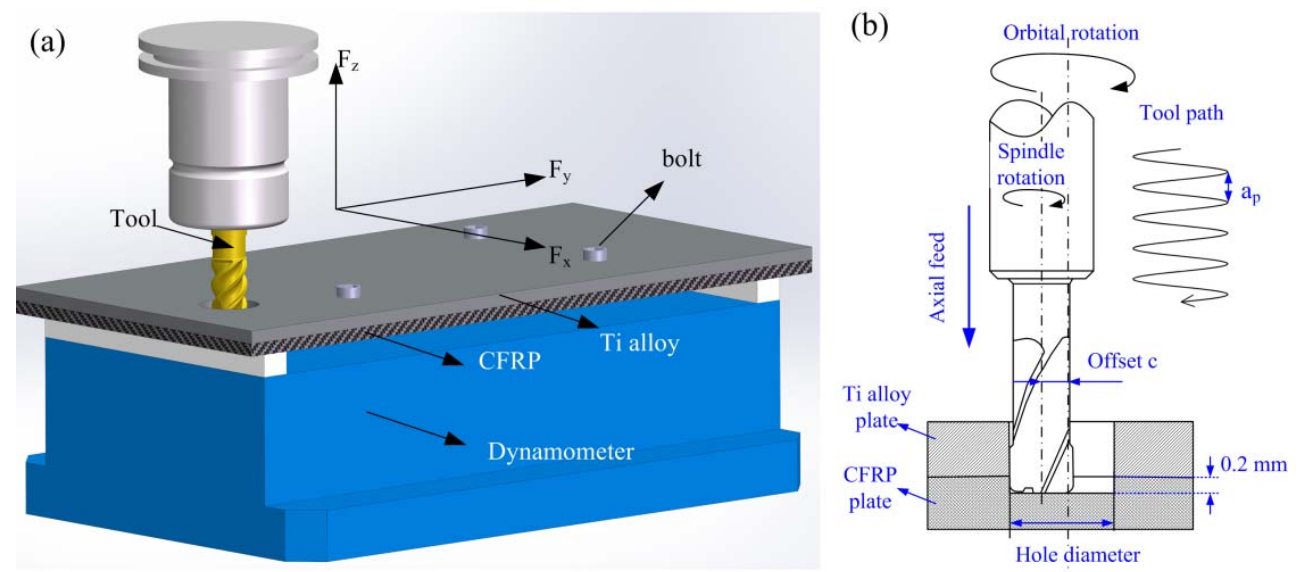

Fig. 3 a Schematic of Ti/CFRP stack under helical milling process, $\mathbf{b}$ schematic of the helical milling kinematics and the time to switch cutting conditions. 
Table 3 Cutting parameters for Ti alloys and CFRP

\begin{tabular}{ccccc}
\hline Cutting & $\begin{array}{c}\text { Spindle speed } \\
\text { parameters }\end{array}$ & $\begin{array}{c}\text { Tangential } \\
\text { feed }\end{array}$ & $\begin{array}{c}\text { Axial feed } \\
a_{p}(\mathrm{~mm} / \mathrm{mev})\end{array}$ & $\begin{array}{c}\text { Offset } \\
(\mathrm{mm} / \text { tooth })\end{array}$ \\
\hline Ti alloys & 3000 & 0.03 & 0.15 & 2 \\
CFRP & 7500 & 0.06 & 0.10 & 2 \\
\hline
\end{tabular}

The machined hole diameters were measured using a three coordinate measuring system and the hole surface roughness was measured by a Mitutoyo SJ-500 surface roughness meter. The hole edge profile was evaluated using a VHX-5000 3D optical microscope. The worn surfaces morphology and its elemental composition were analyzed using SEM and energy dispersive spectrometer (EDS), respectively. The hole edge quality was investigated using a Keyence VHX-600E digital microscope.

\section{Results and discussions}

\subsection{Cutting forces}

Holes were produced along the short side of stack plate and each column accommodated 7 holes. Considering the serious degree of tool wear, 2 colums of holes (14 holes) were produced using each tool selected in the present investigation. Figure 4 shows the cutting force signals during cutting of the $14^{\text {th }}$ hole using a UC tool. Due to the orbital revolution of the tool bit, the cutting forces in $\mathrm{X}$ and $\mathrm{Y}$ directions $\left(F_{x}\right.$ and $\left.F_{y}\right)$ presented very similar sinusoidal pattern, see Figs. $4 a$ and $c$. The mean value of axial cutting force was denoted as $F_{z}$. There was a slight decrease in $F_{z}$ as the milling of Ti alloy progresses (Fig. 4d), which may be due to thermal softening [28] 
caused by the elevated cutting temperature.
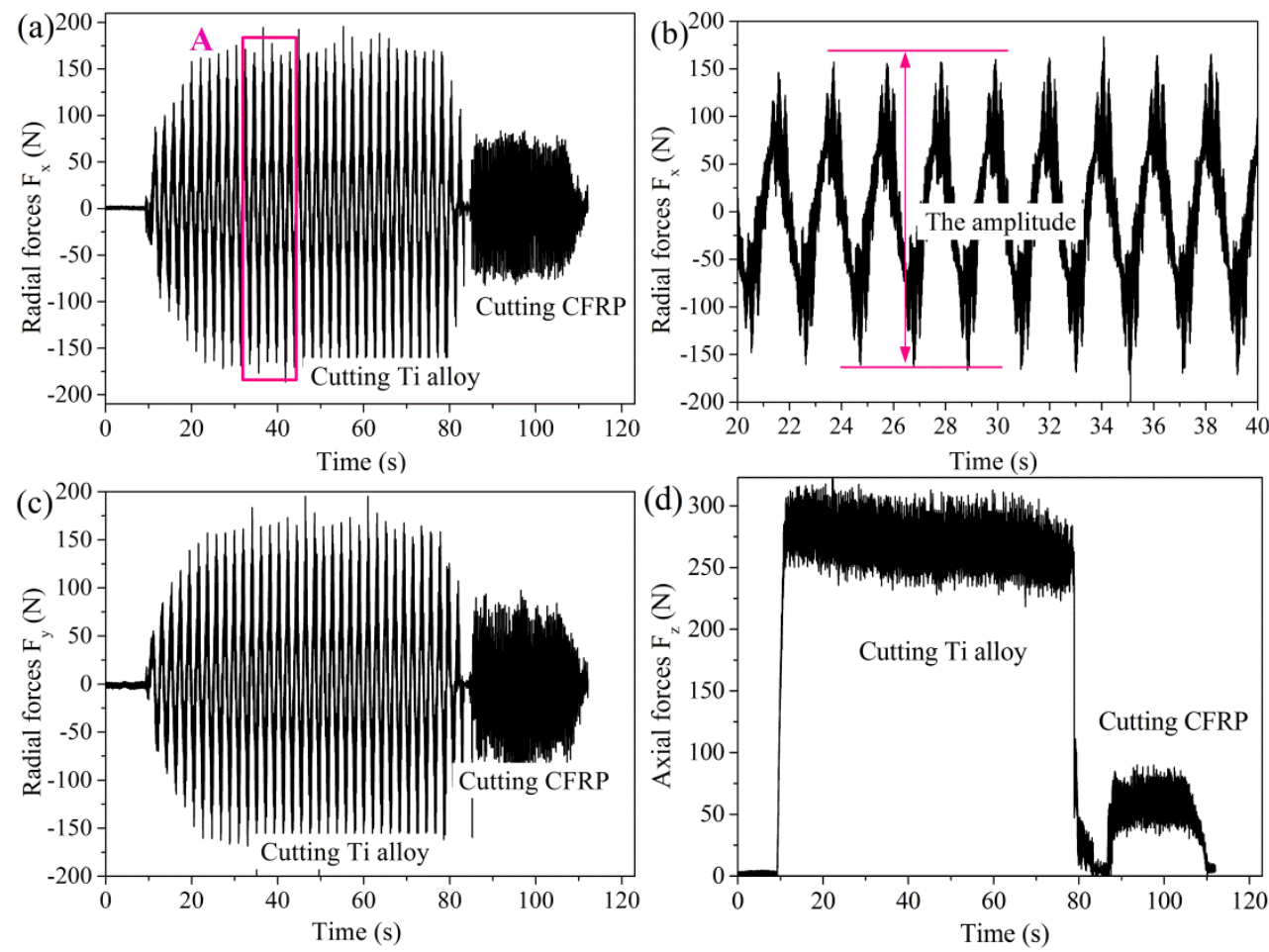

Fig. 4 The typical cutting force signal (from milling of the $14^{\text {th }}$ hole) in helical milling the Ti/CFRP stack, a radial forces $F_{x}, \mathbf{b}$ enlarged zone A for radial forces $F_{x}$, $\mathbf{c}$ radial forces $F_{y}$, $\mathbf{d}$ axial forces $F_{z}$

Figure 5 shows the cutting forces data collected from different tools when cutting the top Ti alloy layer. The maximum forces in the $\mathrm{X}$ and $\mathrm{Y}$ directions were calculated from the half amplitude of the sine curves (average value) in Figs. 4a and c, respectively. It can be seen UC tool generated the lowest cutting forces in all directions whereas DC tool generated the largest cutting forces. It is also worth noting that there is a sudden increase in the radial forces (peaked at the $3^{\text {rd }}$ hole) of the DC tool. The sudden increase is caused by cutting edge chipping in machining process, as shown in Fig. 6, there was an obvious increase when machining the $2^{\text {nd }}$ hole using DC 
tool. While after the $3^{\text {rd }}$ hole, cutting forces increased slowly and seemed to be plateauing, it may be related to the serious Ti adhesion after edge chipping. As the adhered materials generated and worn out, cutting forces fluctuate remarkably. Besides, the increase of cutting temperature caused by chipping may decrease cutting forces due to the thermal softening effect.
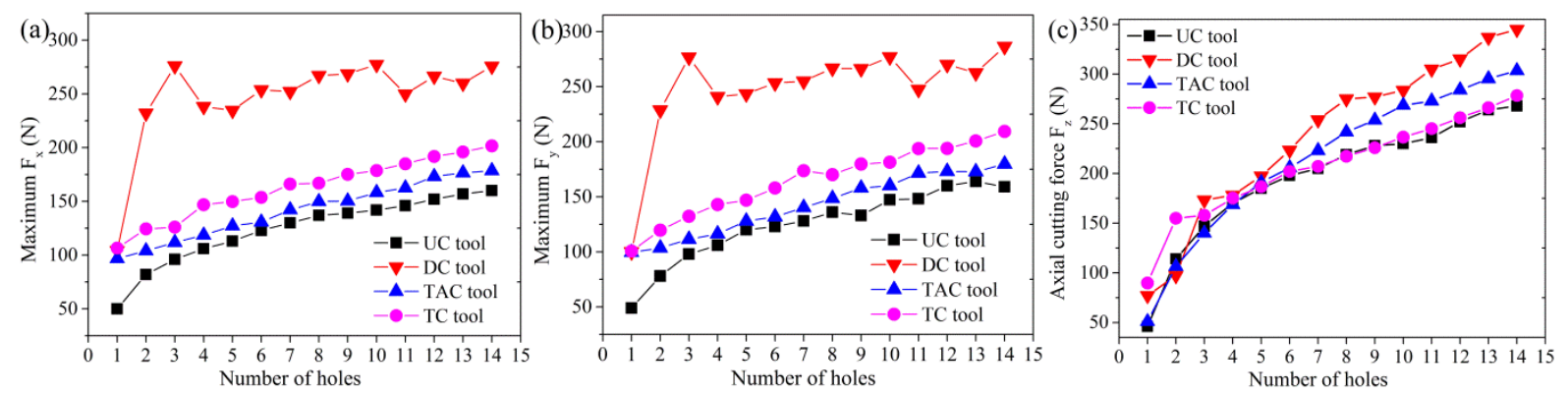

Fig. 5 Cutting forces of different tools in helical-milling of titanium alloy
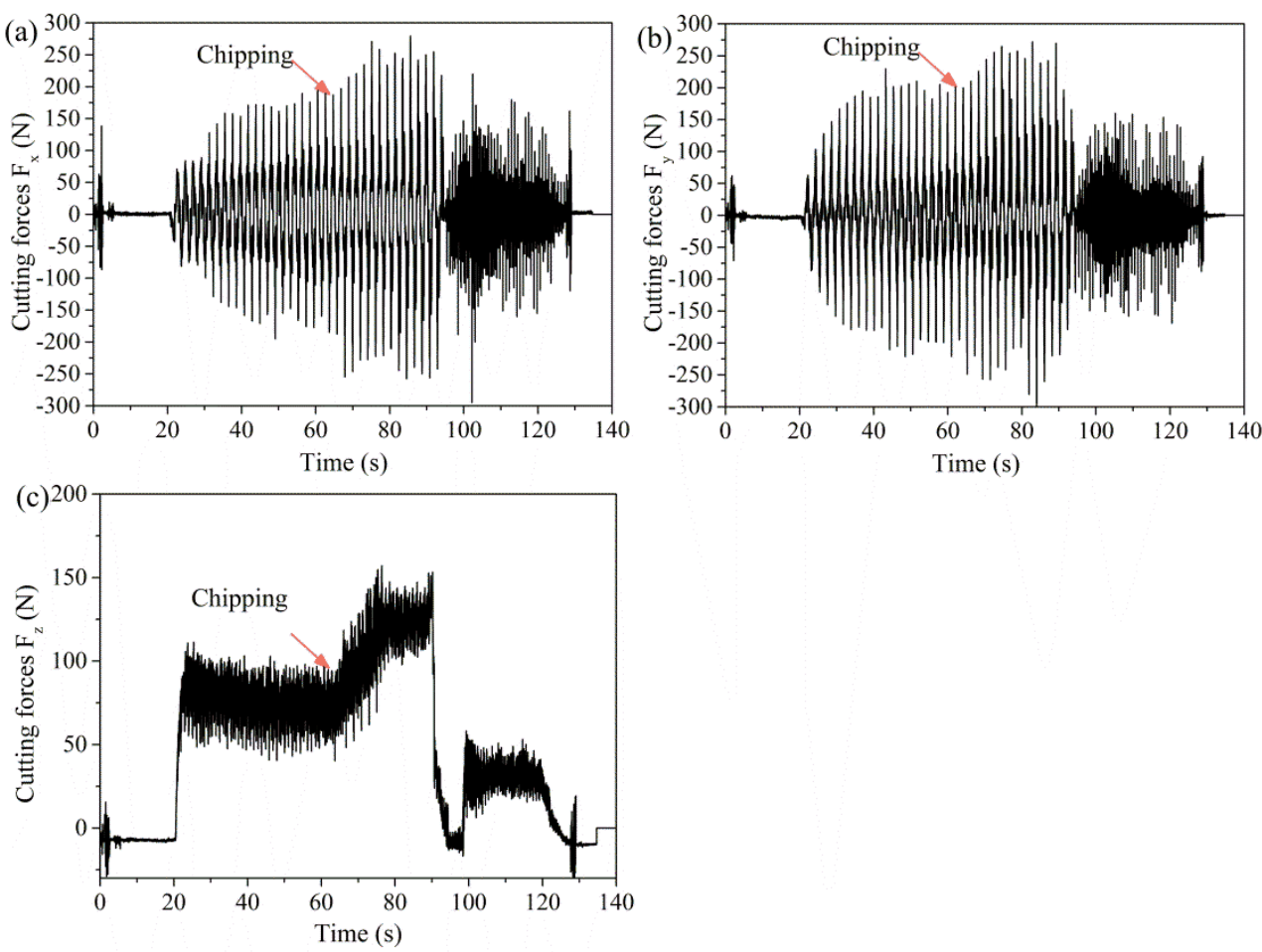

Fig. 6 The cutting force signal in helical milling the $2^{\text {nd }}$ hole, a radial forces $F_{x}, \mathbf{b}$ radial forces $\mathrm{F}_{\mathrm{y}}$, c axial forces $\mathrm{F}_{\mathrm{z}}$ 
The cutting forces resulted from TAC and TC tools are generally greater than that of the UC tool but lower than that of the DC tool. Cutting forces for CFRP follow similar trend as seen for the Ti alloy, except that the level of forces is much lower, see Fig. 7. The differences in cutting force are strongly related to the different tool wear state, which will be discussed in section 3.3.
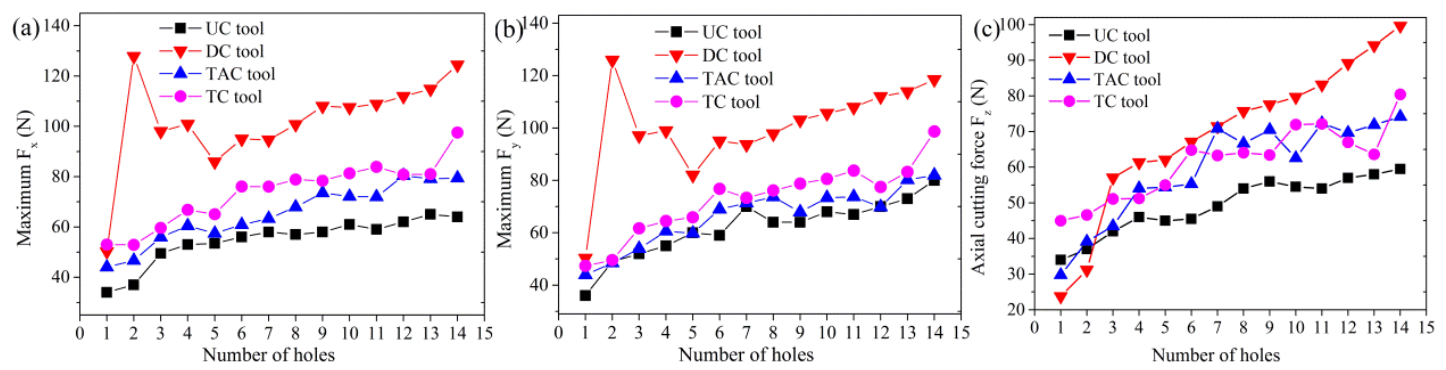

Fig. 7 Cutting forces measured for different tools in helical-milling of CFRP

\subsection{Hole quality evaluation}

\subsubsection{Hole sizes}

Figure 8 shows the hole sizes produced by different tools. In general, hole diameter gradually decreases as the hole number increases, this can be attributed to the gradual tool wear and the increasing tool deflection due to the increased radial cutting forces (see Figs. 5 and 7). The diameters of the first few holes produced by coated tools are slightly larger than expected. It has been associated to two aspects. Firstly, it is ascribed to the added coating, especially the coating near the cutting edge has a larger thickness than that in a flat region (the measured area) [29]. Secondly, Ti adhesion near the cutting edge of coated tools is more serious than uncoated tool (this is demonstrated in section 3.3), it also contributed to the larger hole size. 

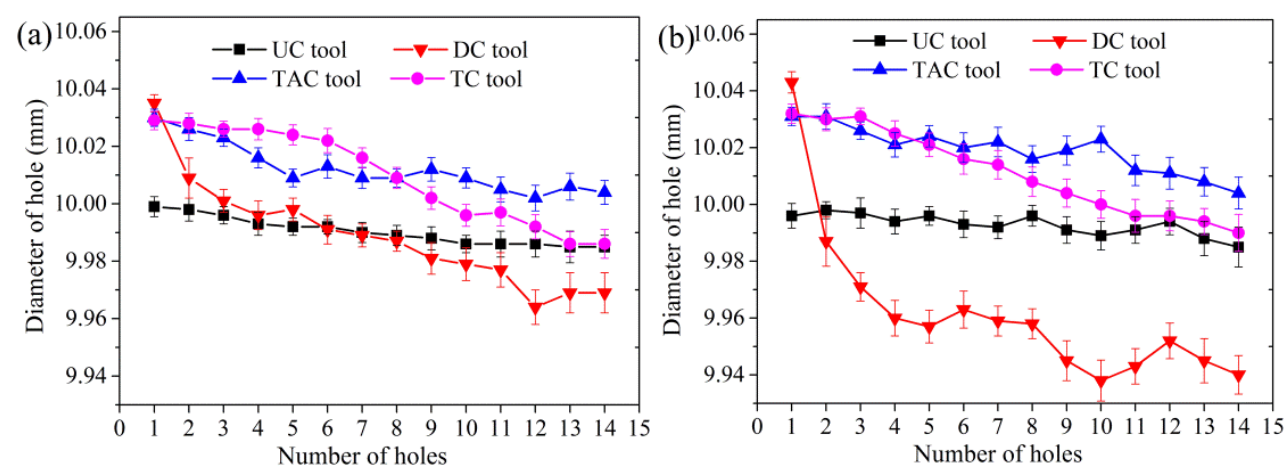

Fig. 8 Diameter of holes as a function of number of hole made in a Ti alloy, $\mathbf{b}$ CFRP

Considering that hole size can be adjusted by the tool offset in the helical milling process, the hole diameter variation under fixed tool offset would therefore be a strong indicator of the hole diameter precision. From Fig. 8, the maximum variation in hole diameter on Ti alloy is produced by the DC tool $(79 \mu \mathrm{m})$, followed by TC tool $(47 \mu \mathrm{m})$, TAC tool $(31 \mu \mathrm{m})$, and UC tool $(14 \mu \mathrm{m})$. The hole diameter variation seen for CFRP follows the same order but with a greater value for each tool, i.e., DC tool $(99 \mu \mathrm{m})>\mathrm{TC}$ tool $(56 \mu \mathrm{m})>\mathrm{TAC}$ tool $(31 \mu \mathrm{m})>\mathrm{UC}$ tool $(18 \mu \mathrm{m})$. The drastic reduction of hole size seen for DC tool is caused by coating flaking and tool chipping, which will be discussed in sections 3.3 and 3.4.

\subsubsection{Surface roughness}

The hole side wall surface roughness $(\mathrm{Ra})$ produced from different milling tools is shown in Fig. 9. For both Ti alloy and CFRP, the side wall roughness increase with increasing hole numbers, with CFRP giving a higher roughness for each hole made. The surface roughness produced by the UC tool and nitrides coated tools are similar, whereas the hole roughness produced by the DC tool was much greater, especially after hole 5. Since same cutting conditions have been used, the difference seen for the finishing surface quality can be related to the various levels of wear at tool cutting 
edge (see section 3.3).
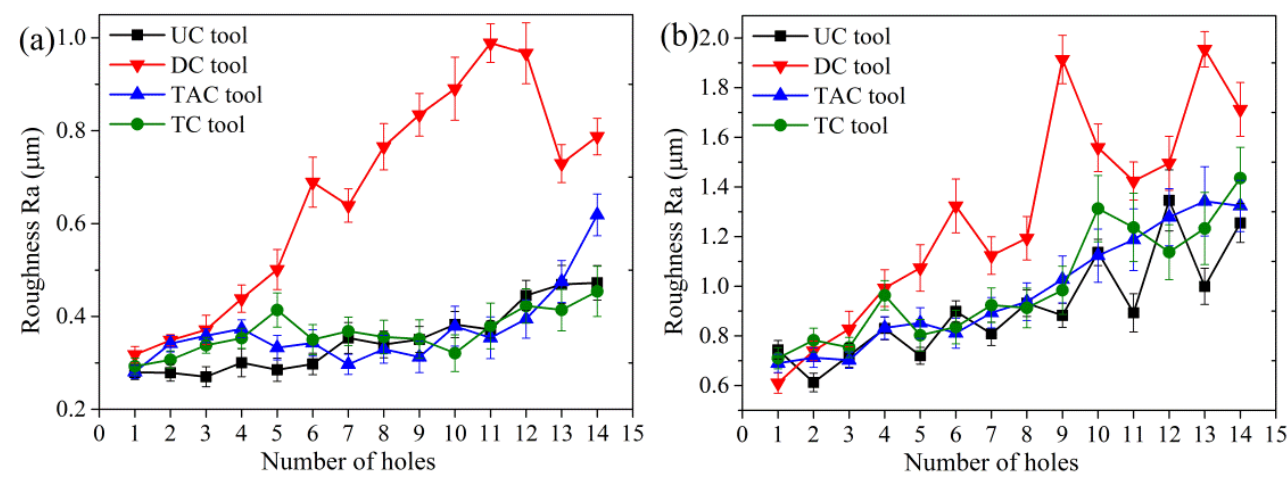

Fig. 9 Hole side wall surface roughness a Ti alloy, b CFRP

\subsubsection{Hole edge quality}

Considering the stacking sequence of the machined work piece (Ti alloy is placed on top of CFRP), the hole edge quality has been evaluated by the burr size at the hole entry (Ti alloy side) and the exit (CFRP side). Since the highest axial force was measured for the $14^{\text {th }}$ holes made and the tools have undergone most degradation at this point, the $14^{\text {th }}$ hole has been selected for detailed investigation and cross-comparison. Figure 10 presents the evaluation process for the burr height at $\mathrm{Ti}$ side. The optical image and its corresponding 3D/2D profiles of the burrs were measured. Burr heights can be determined from the 2D profile. The burr heights produced by different tools at the Ti alloy hole entry have been plotted in Fig. 11. It can be seen that the burr height produced by the DC tool increased abruptly and peaked at the $4^{\text {th }}$ hole $(\sim 0.3 \mathrm{~mm})$. On the other hand, burr heights produced by the TAC and TC tools gradually increased to $0.22 \mathrm{~mm}$ and $0.27 \mathrm{~mm}$, respectively. The UC tool gives the slowest increase in burr height as more holes are being made, and the burr height reached the maximum value of $0.14 \mathrm{~mm}$ at the $14^{\text {th }}$ hole. The burr size change is very similar to the cutting force changing trend during helical milling of $\mathrm{Ti}$ 

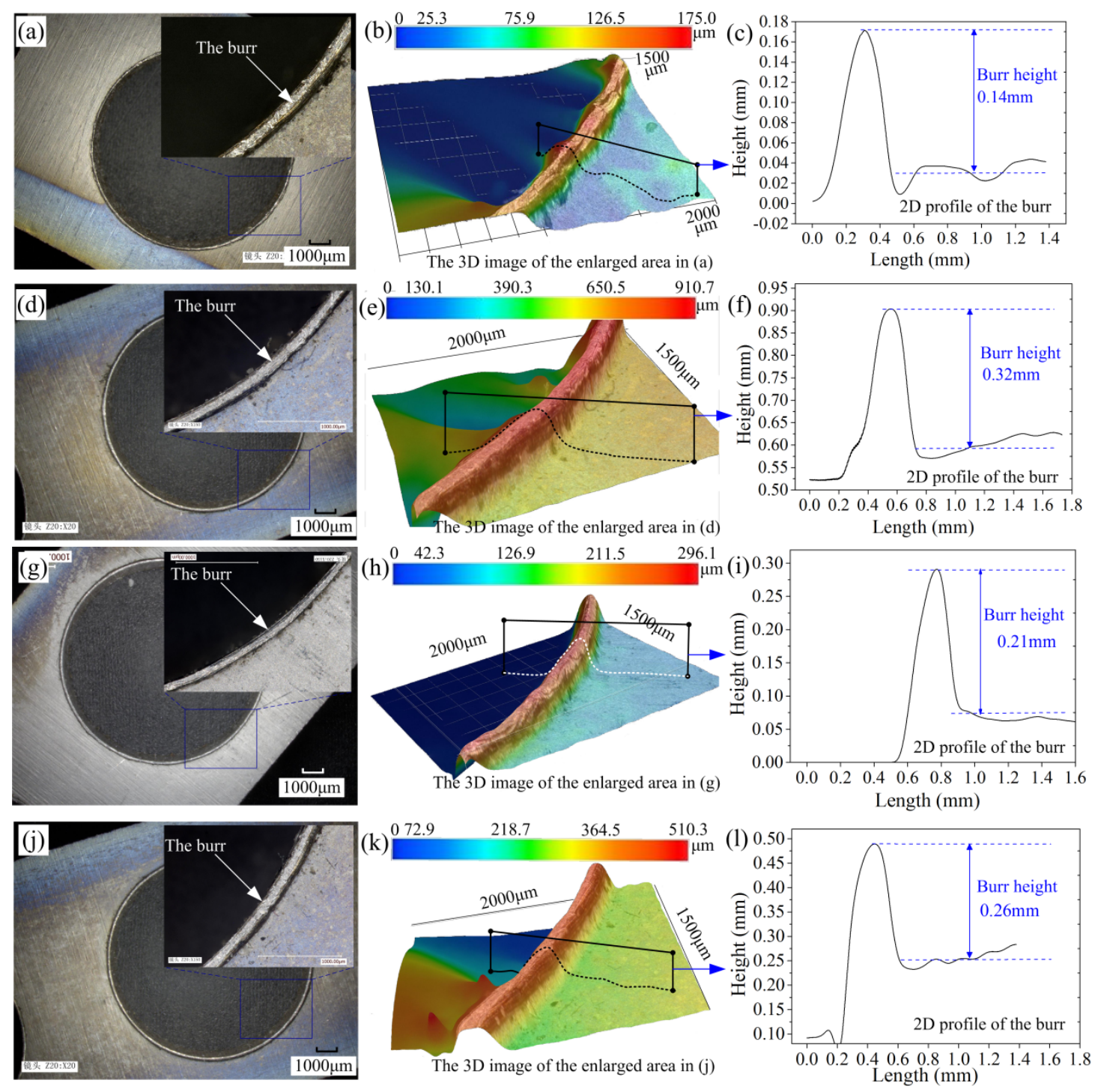

Fig. 10 Evaluation of the burr height of the $14^{\text {th }}$ holes on Ti alloy produced by a $\sim \mathbf{c}$ UC tool, $\mathbf{d} \sim \mathbf{f}$ DC tool, $\mathbf{g} \sim \mathbf{i}$ TAC tool and $\mathbf{j} \sim \mathbf{l}$ TC tool using a VHX-5000 3D optical microscope

alloys (see Fig. 5), suggesting that the increase in cutting force is an important factor contributing to the burr growth.

The defect at the hole exit on the CFRP side shows a completely different morphology, as shown in Fig. 12. Different degrees of burrs and splits were observed at the hole exit for different tools used. Since the CFRP was placed at the bottom of 
the stack, it is more prone to form burrs and splits. Figure 12 shows that the UC tools produced the smallest burrs and splits whereas DC tool produced the largest burrs and splits, which is owing to the highest axial forces exhibited by the DC tool.

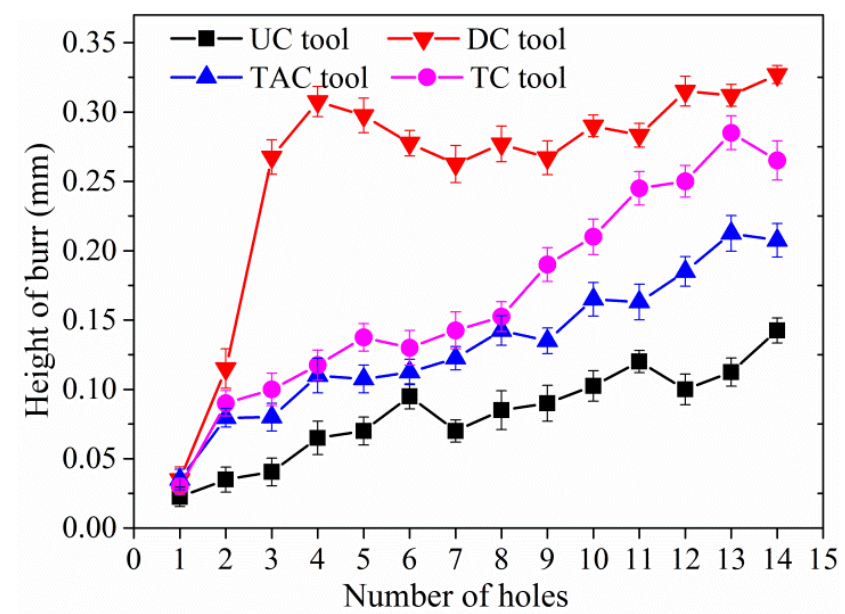

Fig. 11 Height of burrs produced by different tools at the Ti alloy hole entry
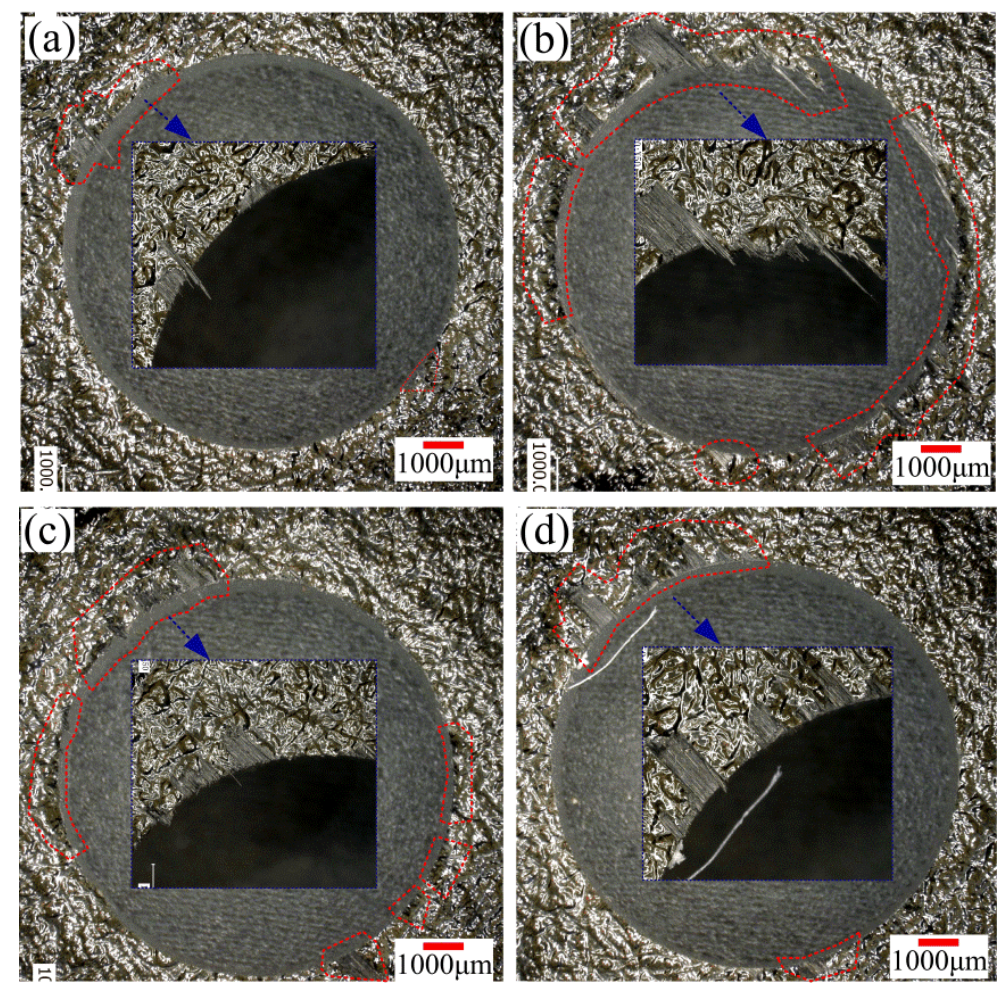

Fig. 12 Optical images showing the burrs and splits at the $14^{\text {th }}$ hole exit of CFRP, a UC tool, b DC tool, $\mathbf{c}$ TAC tool, $\mathbf{d}$ TC tool 


\subsection{Tool wear}

Figure 13 shows the flank faces of the tool end cutting edges after milling 14 holes. It is observed that the degradation of the UC tool was very mild (Figs. 13a and b). No titanium has been detected on the worn tool surfaces from the EDS analysis (see Fig. 13c). On the other hand, the DC tool exhibited severe flaking. Figures 13d and e show a typical image of a worn pit formed on the cutting edge of DC tool as a
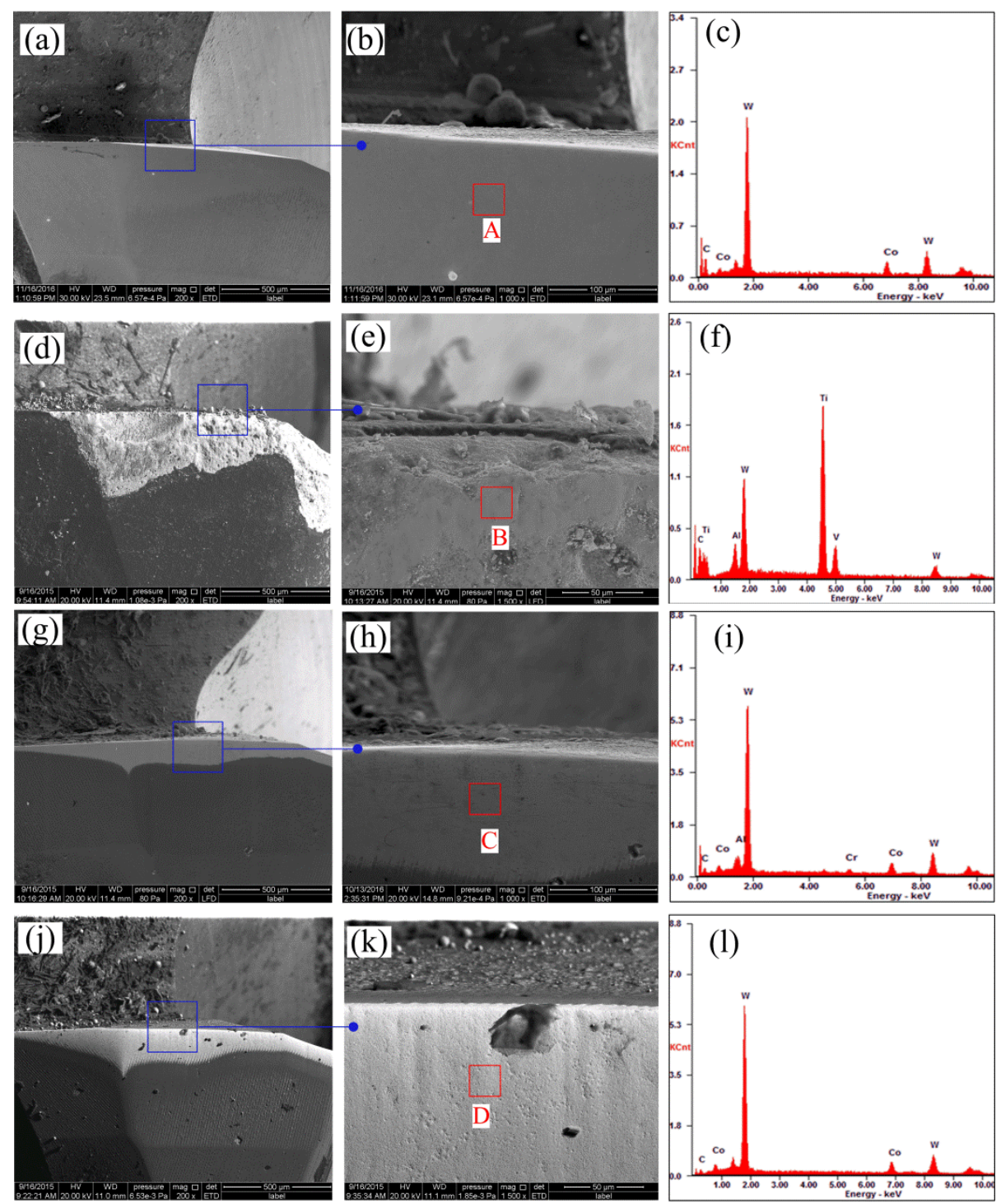

Fig. 13 SEM images of flank faces on the tool end cutting edge after milling 14 holes and their corresponding EDS spectra: $\mathbf{a} \sim \mathbf{c}$ UC tool, $\mathbf{d} \sim \mathbf{f}$ DC tool, $\mathbf{g} \sim \mathbf{i}$ TAC tool, $\mathbf{j} \sim \mathbf{m}$ TC tool 
result of edge chipping. In addition, adhesive wear has occurred on the worn DC tool surface, which is clearly evidenced by the intense Ti peak in the EDS spectrum, see Fig. 13f. The TAC tool (Figs. 13g-i) and TC tool (Figs. 13j-1) exhibited similar degree of moderate degradation, worn coatings were found near the cutting edge, but no evident adhesive wear or flaking took place on the tool end edges.

SEM images of the flank faces on the peripheral cutting edges of different tools are shown in Fig. 14. The tool degradation and Ti adhesion on the UC tool were not significant and the tool cutting edge remains largely intact, as shown in Figs. 14a-c. For the DC tool, however, serious coating flaking and cutting edge chipping have been observed, see Figs. 14e-f. In addition, a layer of adhered Ti has built up in the worn region, as shown in Fig. 14g. For TAC (Figs. 14i-k) and TC (Figs. 14m-o) tools, severe adhesive wear occurred on the flank face of the tool nose (E and $G$ regions). For regions $\mathrm{F}$ and $\mathrm{H}(\sim 2.5 \mathrm{~mm}$ away from the tool nose), micro-chipping was observed, which is detrimental to tool performance and processing quality of the holes produced $[30,31]$.

Figure 15 reveals the surface details of tool rake faces after producing 14 holes. Similar to the tool flank face observation, no Ti adhesion or chipping was found on the UC tool rake face, whereas severe coating flaking and Ti adhesion have been observed on the DC tool. Moderate adhesive wear has occurred on the TAC and TC tool rake faces, accompanied by micro chipping on the peripheral cutting edge. Overall, the wear levels of the tools can be arranged in an ascending order of UC tool, TAC tool, TC tool and DC tool. Tool wear can directly affect cutting force, it is the 
reason that the cutting forces produced by UC tool are the lowest and those produced by DC tool are the largest, as shown in Figs. 5 and 7.
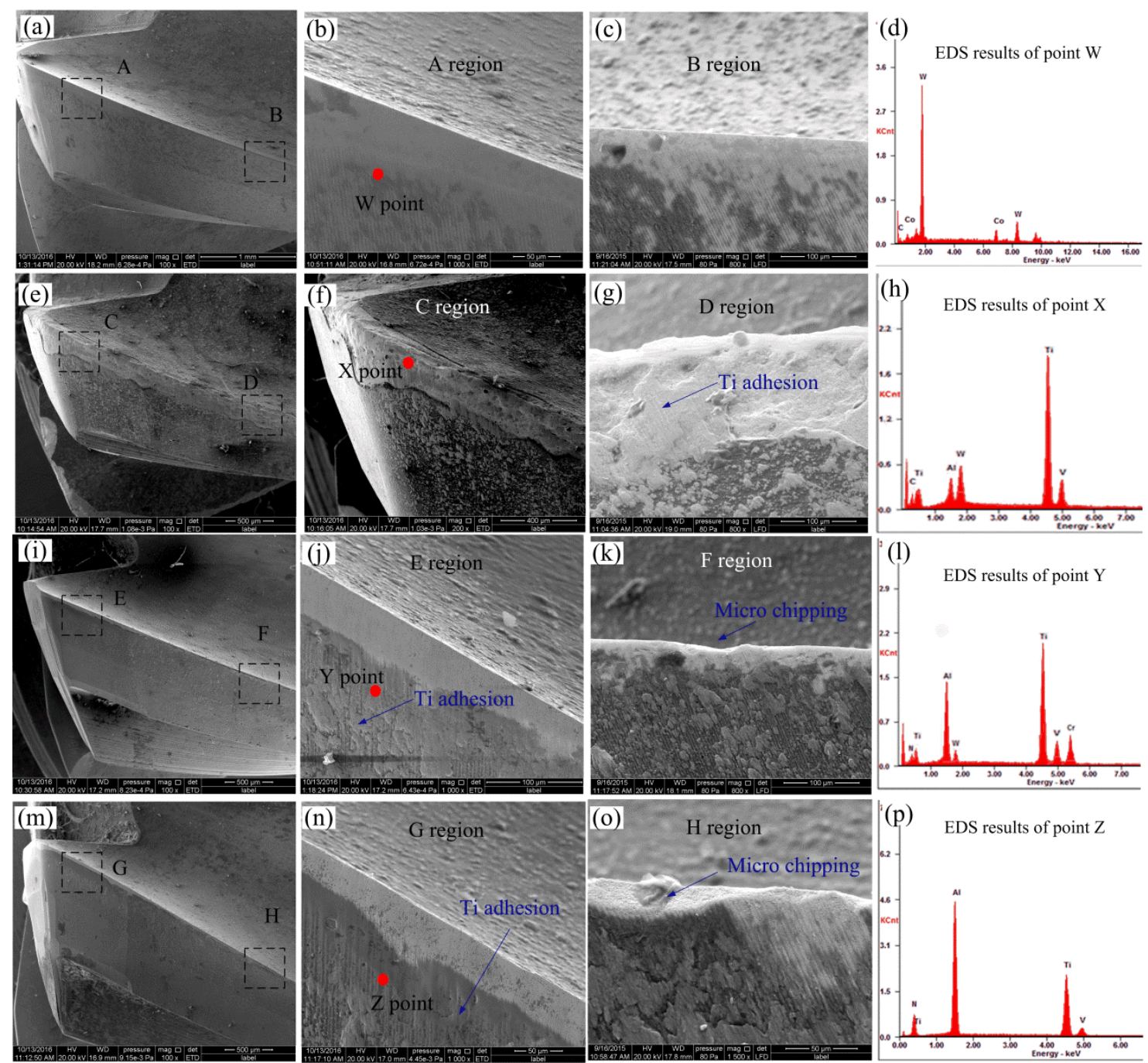

Fig. 14 SEM images of flank faces on the tool peripheral cutting edge after milling 14 holes: a $\sim \mathbf{d}$ UC tool, $\mathbf{e} \sim \mathbf{h}$ DC tool, $\mathbf{i} \sim \mathbf{l}$ AC tool, $\mathbf{m} \sim \mathbf{p}$ TC tool

\subsection{Discussion}

It is widely accepted that that the use of wear-resistant coatings can prolong the life of cutting tools. However, this study on helical milling of Ti/CFRP stacks shows contradictory results. Compared with coated tools, the uncoated tool has resulted in lower cutting forces, better hole quality and less severe tool wear. The findings are 

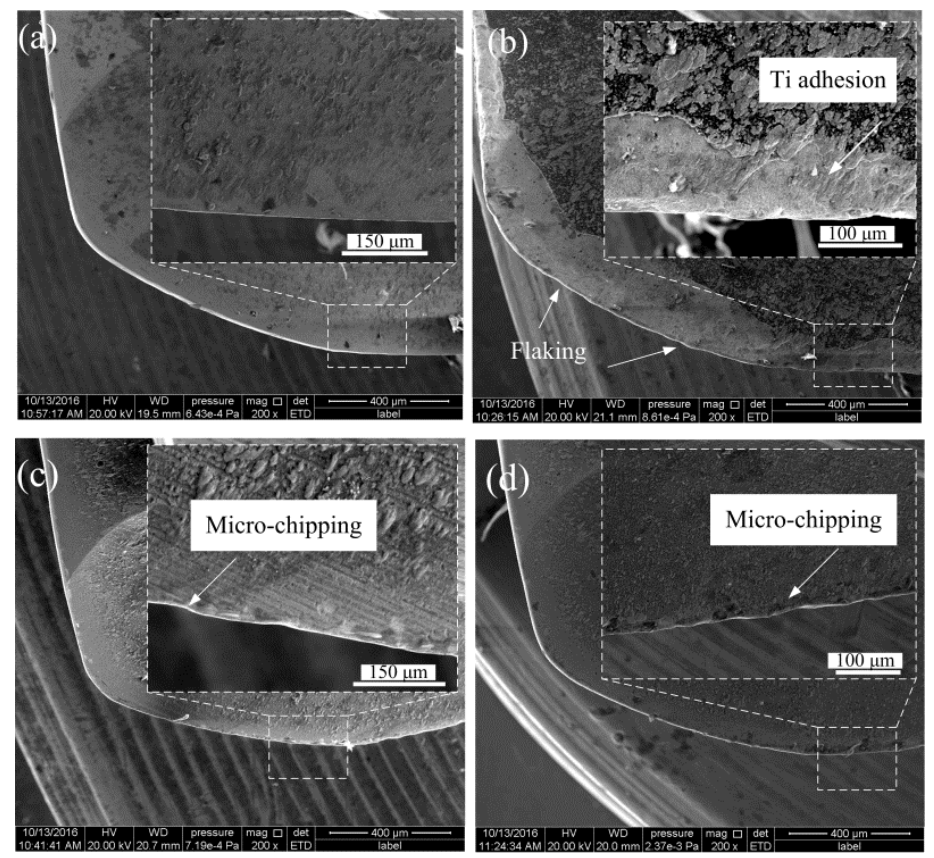

Fig. 15 SEM images of tool rake faces after milling 14 holes: a UC tool, b DC tool, c

TAC tool, $\mathbf{d}$ TC tool

consistent with the results of Mruphy [23] and Shyha [25] in drilling of CFRP. However, the degradation of coated tools in helical milling of Ti/CFRP stacks in the present study is much more complicated because of the intricate wear mechanisms involved during cutting of Ti/CFRP stacks and the differences between helical milling and drilling processes.

\subsubsection{Degradation mechanism of nitride coated tool}

Since the cutting thickness in helical milling of Ti/CFRP is small $(0.3 \sim 0.5$ $\mu \mathrm{m} /$ tooth for the end cutting edge and 30 60 $\mu \mathrm{m} /$ tooth for the peripheral cutting edge in this paper), the tool performance and hole quality are strongly dependent on the roundness of cutting edge [32]. On the other hand, the coating layer can greatly affect the cutting edge radius of the coated tool. The sharp geometry of the cutting edge 
(hence a higher residual stress concentration) can lower the coating bonding strength $[33,34]$, making them more prone to flaking and subsequent degradation. In addition, it is generally accepted that tool wear under machining of CFRP is mainly concentrated on the cutting edge $[17,32,35]$. When machining the Ti/CFRP stacks, the cutting tools are subjected to a higher residual temperature (as a result of machining the top Ti alloy), this would accelerate the cutting edge wear during the subsequent machining process. Therefore, machining of Ti/CFRP stacks would cause rapid damage of the coating under the coupled effect of the weak mechanical stability of coating and the concentrated wear at the cutting edge. In this case, a visible increase in the roundness of tool cutting edge occurred, leading to the formation a micro negative chamfer, as is shown in Figs. 16a d (for simplicity, only SEM images of TC tools have been selected for illustration purpose in Fig. 16).

In this study, the edge radius before coating deposition is $\sim 2 \mu \mathrm{m}$ and the coating thickness is in the range of $2 \sim 7 \mu \mathrm{m}$. Therefore, the coating flaking at the cutting edge can significantly affected the tool sharpness and its machining performance. As a result, cutting forces and cutting temperature will increase, leading to greater $\mathrm{Ti}$ adhesion. More importantly, the increased cutting forces will impose much greater cyclic impact stress on the peripheral cutting edges of the cutting tools, resulting in micro-chipping of the tool edge (see Figs. 16c and d). Such worn cutting edge subsequently led to the poor diameter consistency and greater burr size at the hole entry and exit. For these reasons, the deteriorated coating actually accelerated the cutting edge wear through edge rounding, as shown in Figs. 16e and f. 
The force generated directly by the cutting edge is called ploughing force. It is

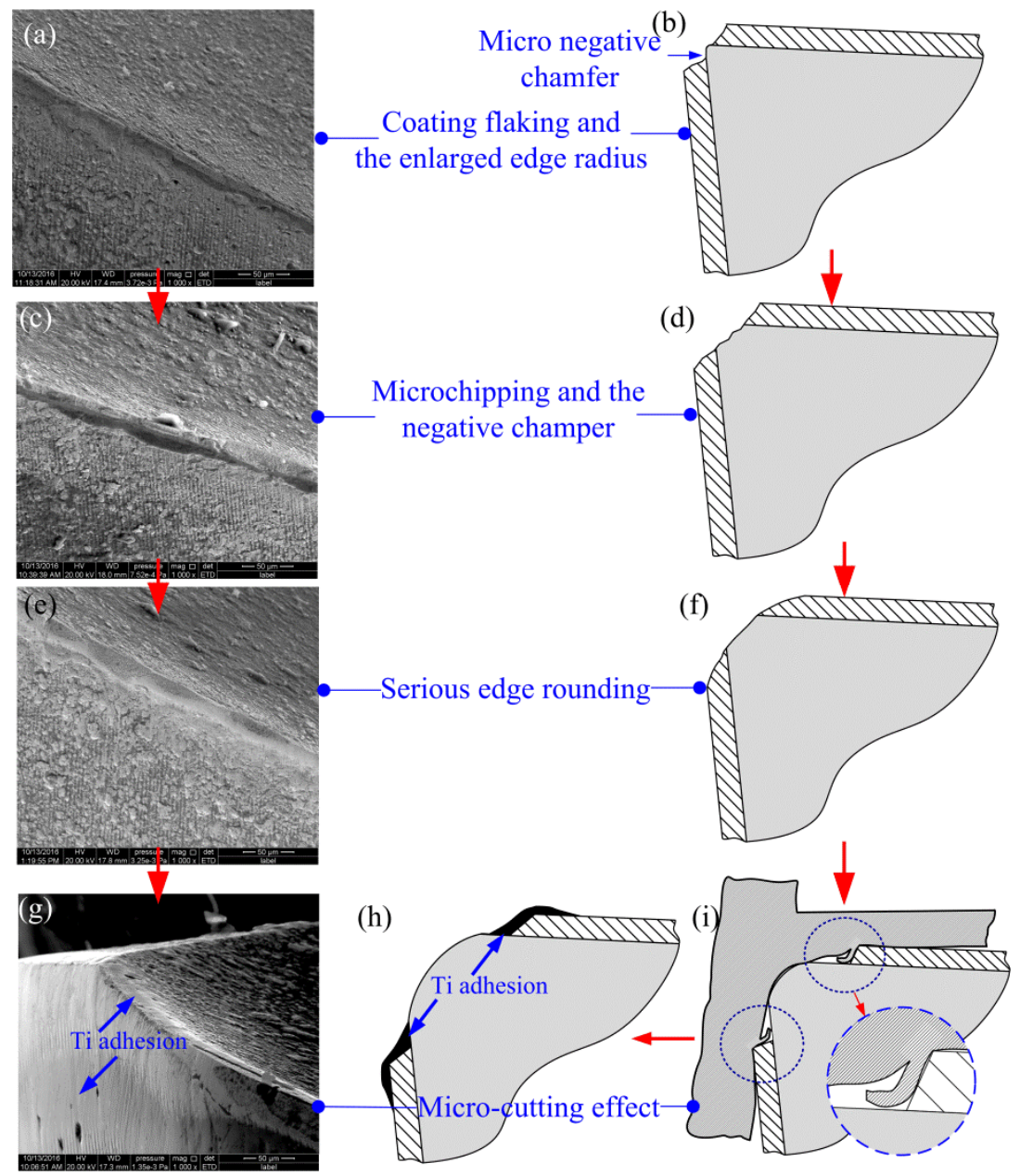

Fig. 16 Worn tool surface morphologies of typical TC tool after milling a 2 holes, c and e 4 holes, $\mathbf{g} 14$ holes, and their corresponding schematic showing the evolution of the cutting edge wear processes

sensitive to edge wear and treated as an indicator of cutting edge wear. [36] The edge ploughing force can be extrapolated through the relationship of cutting force and cutting thickness [37-39]. To compare the edge wear of these tools more clearly, ploughing forces were extrapolated. Due to the complex components of axial forces (produced by end and peripheral edges) and axial feed rate per tooth (determined by 
$a_{p}$ and $f_{p t}$ ), axial forces under different cutting thickness are difficult to analyze quantitatively as a signal factor. While radial force is only produced by peripheral edges and the peripheral feed rate is also only determined by $f_{p t}$, so the relationship between radial forces and peripheral feed rate $\left(f_{p t}\right)$ is easy to be obtained. Thus radial force ( $F_{x}$ or $F_{y}$, half amplitude of the sine curve) is selected to extrapolate ploughing force. It is noted that by this method the ploughing force is only part of ploughing force of peripheral edge due to ignoring axial force, but it still can reflect cutting edge wear clearly.

Radial cutting forces under different peripheral feed rate $(0.01 \sim 0.07 \mathrm{~mm} /$ tooth for Ti alloys and $0.03 \sim 0.10 \mathrm{~mm} /$ tooth for CFRP) were measured using tools after cutting 0 , 5, 10 and 14 holes under the cutting conditions of Table 3, so the relationship between radial force and peripheral cutting feed rate under different tool worn stages are obtained. Figures $17 \mathrm{a}$ and $\mathrm{b}$ show the extrapolating process of UC tool and Fig. 17c and $\mathrm{d}$ show all the ploughing force results.
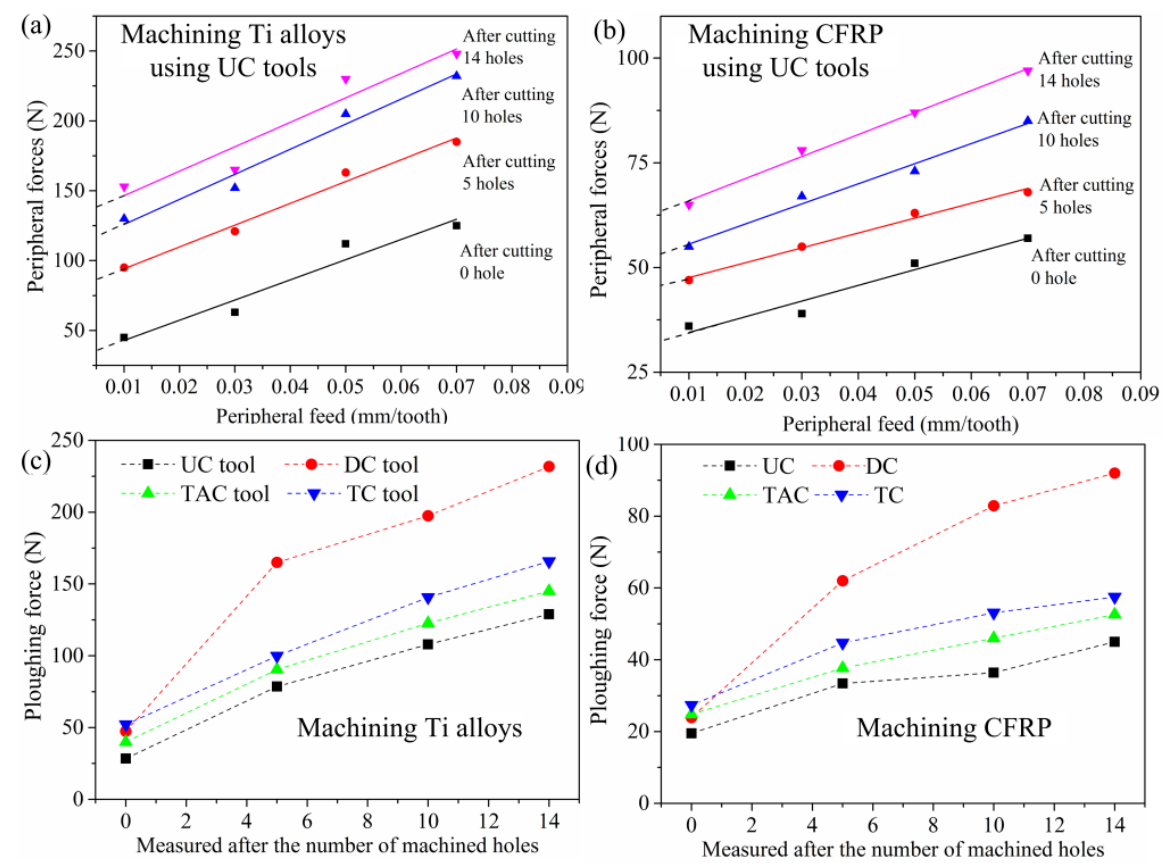
Fig. 17 The extrapolated process of ploughing force using UC tools when machining of a Ti alloys and $\mathbf{b}$ CFRP at different worn stage, and the extrapolated ploughing forces when machining of $\mathbf{c}$ Ti alloys and $\mathbf{d}$ CFRP.

From these results, it can be seen that the ploughing force increment in tool early wear stages is larger than that in later wear stages, suggesting that edge rounding is faster in the early wear stages. The ploughing forces can be generally placed in an ascending order as: UC tool, TAC tool, TC tool and DC tool, which reflects cutting edge wear degree of different tools, which proves that coated tools had more serious edge wear than uncoated tool in helical milling of Ti/CFRP stacks.

Besides, the deteriorated coating on the flank face and the rake face will exert a micro-cutting action on the cutting chips and the machined surface, as shown in Figs. $16 \mathrm{~g} \sim \mathrm{i}$. Such micro-cutting mechanism could aggravate the friction between the machined surface and the flank face, and increase the adhesive wear on the rake face as well as the flank face of the tool. On the other hand, the abrasive effect of the micro-cutting edge and the Ti adhesion layer could "polish" the machined surface. This will compensate some of the aggravation caused by the micro-chipping and make the resulting hole side wall roughness comparable to those produced by uncoated tools (see Fig. 9).

\subsubsection{Degradation mechanism of DC tool}

The degradation mechanisms for diamond coated tool are significantly different from those of the nitrides coated tools. Figure 18 shows the wear morphology of zone 
A in Fig. 1 at different machining stages. It is obvious that chipping took place at the initial machining stage, which is one major reason for the catastrophic performance of the DC tool. According to the EDS analysis, the Co content of cemented carbides in zone A of Fig. 2a is only 3 6 wt.\%, This is a result of the commonly used pre-treatment process for reducing the Co content in the WC/Co carbides in order to improve the coating bonding strength [40]. However, such low Co content significantly reduces the ductility of the cutting edge and directly causes the serious chipping experienced by the tool. On the other hand, the compatibility between the diamond coating and the cemented carbide was not good enough to prevent the heavy flaking on the DC tool. In addition, the graphitization and oxidation of diamond coating under high cutting temperature would also accelerate the coating degradation and bring down its protection function [41].
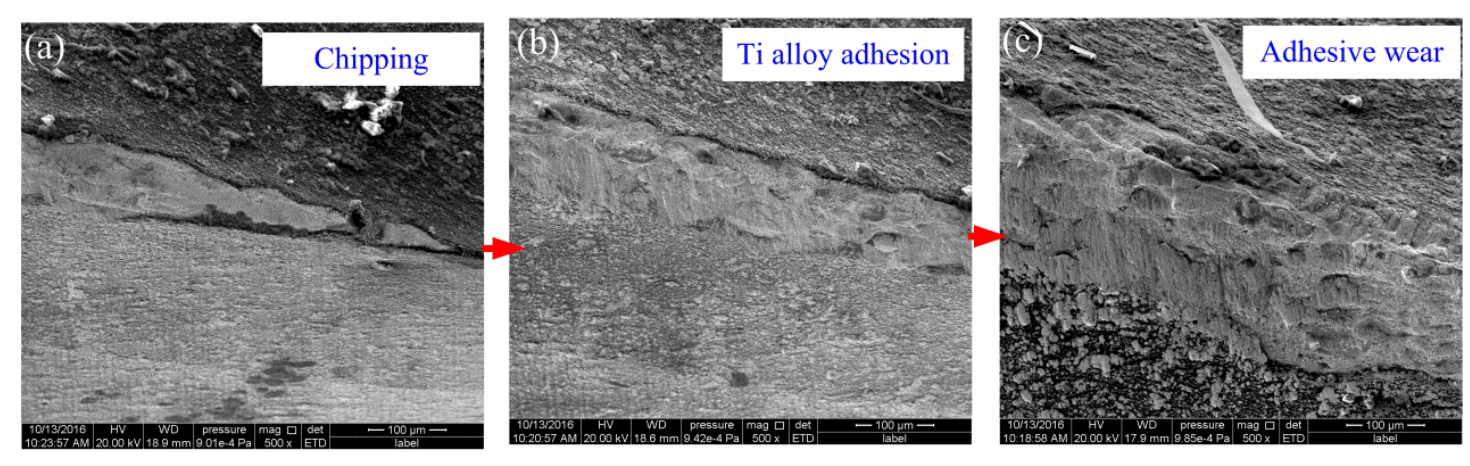

Fig. 18 SEM images of DC tools showing chipping and adhesive wear, after milling a 2 holes, b 4 holes, $\mathbf{c} 14$ holes

\section{Conclusion}

In this work, the helical milling performance of Ti/CFRP stacks by using different coated tools has been compared. The cutting force, hole quality, tool wear morphology and degradation mechanisms have been investigated in details. From the 
results, the following conclusions can be drawn:

1. The uncoated tool outperforms the coated tools in helical milling of Ti/CFRP stacks. The uncoated tool gives a smaller cutting forces, better hole diameter consistency and lower hole surface roughness. The diamond coated tool gives the least satisfying performance due to the poor hole quality resulted from the aggravated tool degradation.

2. After milling 14 holes, serious coating flaking, adhesive wear and chipping occurred on diamond coated tool. For nitrides coated tools, adhesive wear and micro-chipping occurred on the peripheral cutting edge. While uncoated tool had minimum adhesive wear without any chipping.

3. The poor performance of nitrides coated tools is mainly attributed to the combination action of the increased roundness of cutting edge caused by tool coating and the strong dependence of cutting performance on the tool sharpness. For the diamond coated tool, the low ductility of tool cutting edge, weak coating/substrate bonding strength and the poor coating thermal stability have contributed to its severe tool degradation.

From the findings of this research, it is concluded that uncoated $\mathrm{WC} / \mathrm{Co}$ tools are more appropriate for the helical milling of Ti/CFRP stack structure than the diamond, TiAlN + AlCrN or TiAlN coated tools. Further advances in tool manufacturing to reduce the negative effect of coating on the tool sharpness and improve the coating adhesive strength at cutting edge, such as suitable edge preparation and reducing coating thickness, would improve the existing coated tool performance. However, this 
requires more detailed investigation and development in future.

\section{Acknowledgements}

This work was supported by "the National Natural Science Foundation of China (51605326)", “the Natural Science Foundation of Tianjin (16JCZDJC38300)", "EU H2020 RISE 2016---ECSASDPE 734272” and British Council UK-China Knowledge Economy Education Partnership Award.

\section{References}

[1] Luo B, Li Y, Zhang K, Cheng H, Liu S (2015) A novel prediction model for thrust force and torque in drilling interface region of CFRP/Ti stacks. Int J Adv Manuf Technol 81:1497-1508.

[2] Kim D, Beal A, Kwon P (2016) Effect of tool wear on hole quality in drilling of carbon fiber reinforced plastic-titanium alloy stacks using tungsten carbide and polycrystalline diamond tools. J Manuf Sci Eng 138:31006.

[3] Nor Khairusshima MK, Che Hassan CH, Jaharah AG, Amin AKM, MdIdriss AN (2013) Effect of chilled air on tool wear and workpiece quality during milling of carbon fibre-reinforced plastic. Wear 302:1113-1123.

[4] Schroeder PT (1998) Widening interest in twist drills. Modern Mach. Shop 71:106-113.

[5] Urbicain G, Olvera D, Lacalle LNLD, Zamakona I, Rodal P (2009) New strategies for hole making in Ti-6Al-4V. AIP Conference Proceedings 1181:361-369.

[6] Brinksmeier E, Fangmann S, Rentsch R (2011) Drilling of composites and resulting surface integrity. CIRP Ann-Manuf Technol 60:57-60.

[7] Ni W (2007) Orbital Drilling of Aerospace Materials. SAE Technical Paper 01:3814-3822.

[8] Denkena B, Boehnke D, Dege JH (2008) Helical milling of CFRP-titanium layer compounds. CIRP J Manuf Sci Technol 01:64-69.

[9] Li H, Qin X, He G, Jin Y, Sun D, Price M (2016) Investigation of chip formation and fracture toughness in orthogonal cutting of UD-CFRP. Int J Adv Manuf Technol 82: 1079-1088. 
[10] Sun D, Lemoine P, Keys D, Doyle P, Malinov S, Zhao Q, Qin XD (2016) Hole-making processes and their impacts on the microstructure and fatigue response of aircraft alloys. Int $\mathrm{J}$ Adv Manuf Technol. doi:10.1007/ s00170-016-9850-3.

[11] Tian Y, Liu Y, Wang F, Jing X, Zhang D, Liu X (2017) Modeling and analyses of helical milling process. Int J Adv Manuf Technol 90:1003-1022.

[12]Zhao Q, Qin X, Ji C, Li Y, Sun D, Jin Y (2015) Tool life and hole surface integrity studies for hole-making of Ti6A14V alloy. Int J Adv Manuf Technol 79:1017-1026.

[13]Ezugwu EO, Wang ZM (1997) Titanium alloys and their machinability-a review. J Mater Process Technol 68:262-274.

[14]Qin X, Zhang X, Li H, Rong B, Wang D, Zhang H, Zuo G (2014) Comparative analyses on tool wear in helical milling of Ti-6Al-4V using diamond-coated tool and TiAlN-coated tool. J Adv Mech Des Syst 8:JAMDSM0004.

[15] Ishida T, Noma K, Kakinuma Y, Aoyama T, Hamada S, Ogawa H, Higaino, T (2014) Helical milling of carbon fiber reinforced plastics using ultrasonic vibration and liquid nitrogen. Procedia CIRP 24:13-18.

[16]Park K, Beal A, Kim DD, Kwon P, Lantrip J (2014) A comparative study of carbide tools in drilling of CFRP and CFRP-Ti stacks. ASME J Manuf Sci Eng 136:014501-014509.

[17] Ramirez C, Poulachon G, Rossi F, M'Saoubi R (2014) Tool wear monitoring and hole surface quality during CFRP drilling. Procedia CIRP 13:163-168.

[18]Liu D, Tang Y, Cong WL (2012) A review of mechanical drilling for composite laminates. Compos Struct 94: 1265-1279.

[19]He G, Li H, Jiang Y, Qin X, Zhang X, Guan Y (2015) Helical milling of CFRP/Ti-6Al-4V stacks with varying machining parameters. Trans Tianjin Univ 21:56-63.

[20]Pecat O, Brinksmeier E (2014) Tool wear analyses in low frequency vibration assisted drilling of CFRP/Ti6Al4V stack material. Procedia CIRP 14:142-147.

[21]Zitoune R, Krishnaraj V, Almabouacif BS, Collombet F, Sima M, Jolin A (2012) Influence of machining parameters and new nano-coated tool on drilling performance of CFRP/Aluminium sandwich. Compos Part B 43:1480-1488.

[22] Park K, Kwon P, Kim D (2012) Wear characteristic on BAM coated carbide tool in drilling of composite/titanium stack. Int J Precis Eng Man 13:1073-1076.

[23] Murphy C, Byrne G, Gilchrist MD (2002) The performance of coated tungsten carbide drills when machining carbon fibre-reinforced epoxy composite materials. Proc Inst Mech Eng Part B 216:143-152. 
[24] Wang X, Kwon PY, Sturtevant C, Kim DD, Lantrip J (2013) Tool wear of coated drills in drilling CFRP. J Manuf Process 15:127-135.

[25] Shyha IS, Aspinwall DK, Soo SL, Bradley S (2009) Drill geometry and operating effects when cutting small diameter holes in CFRP. Int J Mach Tool Manu 49:1008-1014.

[26] Wang H, Qin X, Li H (2015) Machinability analysis on helical milling of carbon fiber reinforced polymer. J Adv Mech Des Syst 9: JAMDSM0057.

[27]Li H, He G, Qin X, Wang G, Lu C, Gui L (2014) Tool wear and hole quality investigation in dry helical milling of Ti-6Al-4V alloy. Int J Adv Manuf Technol 71:1511-1523.

[28] Wang X, Wang LJ, Tao JP (2004) Investigation on thrust in vibration drilling of fiber-reinforced plastics. J Mater Process Technol 148:239-244.

[29] Kim SS, Han JG, Lee SY (1998) Deposition behaviours of CrN films on the edge area by cathodic arc plasma deposition process. Thin Solid Films 334:133-139.

[30] Ezugwu EO (2005) Key improvements in the machining of difficult-to-cut aerospace superalloys. Int J Mach Tool Manu 45:1353-1367.

[31] Gu J, Barber G, Tung S, Gu R (1999) Tool life and wear mechanism of uncoated and coated milling inserts. Wear 225-229:273-284.

[32]Faraz A, Biermann D, Weinert K (2009) Cutting edge rounding: An innovative tool wear criterion in drilling CFRP composite laminates. Int J Mach Tool Manu 49:1185-1196.

[33] Wiklund U, Gunnars J, Hogmark S (1999) Influence of residual stresses on fracture and delamination of thin hard coatings. Wear 232:262-269.

[34] Uhlmann E, Koenig J (2009) CVD diamond coatings on geometrically complex cutting tools. CIRP Ann-Manuf Technol 58:65-68.

[35]Park K, Beal A, Kim DD, Kwon P, Lantrip J (2011) Tool wear in drilling of composite/titanium stacks using carbide and polycrystalline diamond tools. Wear 271:2826-2835.

[36] Guo YB, Chou YK (2004) The determination of ploughing force and its influence on material properties in metal cutting. Journal of Materials Processing Technology 148:368-375.

[37]Brown RH and Armarego EJA (1964) Oblique Machining with a Single Cutting Edge. International Journal of Machine Tool Design and Research 4:9-25.

[38]Albrecht PP (1960) New Developments in the Theory of the Metal-Cutting Process: Part I. The Ploughing Process in Metal Cutting. ASME. J. Eng. Ind. 82:348-357.

[39] Wyen CF, Wegener K (2010) Influence of cutting edge radius on cutting forces in 
machining titanium. CIRP Annals-Manufacturing Technology 59:93-96.

[40] Wei Q, Yu ZM, Ashfold MNR, Ye J, Ma L (2010) Synthesis of micro- or nano-crystalline diamond films on WC-Co substrates with various pretreatments by hot filament chemical vapor deposition. Appl Surf Sci 256:4357-4364.

[41] Minton T, Ghani S, Sammler F, Bateman R, Fürstmann P, Roeder M (2013) Temperature of internally-cooled diamond-coated tools for dry-cutting titanium. Int J Mach Tool Manu 75:27-35. 